\title{
1918: O FIM DO SÉCULO XIX, 100 ANOS DEPOIS
}

\author{
José Otaviano da Mata Machado
}

Dulce et decorum est pro patria mori. (Horácio, Odes)

\section{But the past is just the same - and War's a bloody game... Have you forgotten yet?... Look down, and swear by the slain of the War that you'll never forget. (Siegfried Sassoon, “Aftermath: March 1919”)}

O conflito que varreu a Europa e grande parte dos países sob sua influência ou domínio político entre 1914 e 1918 recebeu uma miríade de epítetos: a "Grande Guerra”, a "Guerra de trincheiras", a "Guerra para acabar com todas as guerras". Nenhum destes é hiperbólico: as dimensões do conflito foram sem precedentes em todos os seus aspectos. Sob um ponto de vista geopolítico, foi de fato a primeira guerra de escala mundial; embora a Grã-Bretanha e a França tenham se envolvido em diversas guerras coloniais nos séculos XVIII e XIX, em campos de batalha tão diversos quanto a Índia, a Europa, e a América do Norte, raramente esses conflitos envolviam as outras potências europeias - muito menos todas elas. A Primeira Guerra Mundial envolveu não só Inglaterra e França, como trouxe para as trincheiras a Alemanha e os grandes impérios do século XIX - o Império Austro-Húngaro e o Império Turco-Otomano -, soldados de países coloniais como Índia, Canadá, China e Senegal e, pela primeira vez na história, os Estados Unidos da América - em uma rejeição à célebre advertência de George Washington para que o país nunca se envolvesse em "complicações europeias". (HOBSBAWM, 1994, p. 31)

Sob uma perspectiva militar, a Primeira Guerra Mundial também foi de uma dimensão inédita: antes mesmo da deflagração do conflito, entre 19 e 50 milhões de homens armados estavam a postos em ambos os lados das fronteiras. (HOBSBAWM, 2018, p. 493). As trincheiras que rasgavam a Europa de norte a sul tanto na frente Aliada quanto na das Potências Centrais somavam cerca de 40.000 quilômetros de extensão - o bastante para traçar a circunferência da Terra (FUSSELL, 2000). As tecnologias de morte que vinham sendo desenvolvidas desde o final do século anterior entraram todas em batalha, redefinindo todos os parâmetros de combate conhecidos até então: bombardeios aéreos, armas químicas, metralhadoras e submarinos obrigariam generais de todo o mundo a reescrever seus manuais de guerra, inaugurando o que hoje entende-se como a "guerra moderna".

A introdução dessas novas tecnologias de guerra foi responsável por mais um aspecto no qual a Grande Guerra foi pioneira: a dimensão da morte. Embora as estimativas variem, há algum consenso em torno do número de 10 milhões de baixas militares no conflito 
(PROST, 2014). Até 1914, não havia registro de nenhuma guerra com baixas superiores a um milhão de mortos (HOBSBAWM, 1994, p. 32). A escala de morte do conflito inaugura uma era em que a quantificação de corpos se torna um gesto fútil, pois sua escala representa uma dimensão incompreensível e, principalmente, irrepresentável (NORRIS, 2000, p. 3).

Esta retórica da "irrepresentabilidade" se apresenta repetidamente ao referir-se à Primeira Guerra Mundial. Há um discurso perene que busca localizar nas pilhas de cadáveres em trincheiras, nos bombardeios a alvos civis, na proliferação generalizada de doenças e infecções entre as tropas e na árida devastação da Terra de Ninguém - a extensão de algumas dezenas de metros que separava as trincheiras Aliadas das alemãs - a raiz de uma "crise da representação" que marcaria a arte europeia profundamente, abrindo caminho para a consolidação da linguagem modernista e de suas influências em toda a produção cultural posterior.

Há, contudo, uma aporia em tal retórica: ainda que a experiência da Primeira Guerra Mundial pareça ser marcada por tal irrepresentabilidade, essa experiência foi representada à exaustão em poemas, romances, canções, filmes, pinturas, retratos e até jogos digitais ao longo do último século. As investigações conduzidas pelos estudos literários sobre as narrativas produzidas a partir das experiências da Primeira Guerra Mundial se dedicaram profundamente a compreender essa aporia: como representar o irrepresentável?

A 100 anos do fim do conflito, contudo, uma outra problemática se impõe sobre a representação da Grande Guerra: uma vez que todos os seus sobreviventes já se foram, como entender a experiência irrepresentável e incomunicável da guerra? Como oferecer novas leituras e novas representações quando só é possível se ancorar em representações de segunda mão? Se 1918 é, como entende Hobsbawm, o "fim do século XIX", como ler esse evento histórico hoje no fim do século XX?

Essas inquietações foram o motor condutor dos debates ocorridos entre 12 e 13 de novembro de 2018 na III Jornada do Núcleo de Estudos de Guerra e Literatura da Faculdade de Letras da UFMG, com a temática "1918: O fim do século XIX, 100 anos depois". O evento reuniu estudiosos de diferentes instituições para se debruçar sobre um amplo espectro de narrativas produzidas desde o início da guerra, em 1914, até o centenário de seu encerramento, em 2018. Dentre os objetos de análise encontravam-se de romances canônicos de autores consagrados até narrativas audiovisuais contemporâneas, como filmes de super-herói, histórias em quadrinhos e videogames de guerra. O dossiê que agora publicamos nesse número especial da Revista Literatura e Autoritarismo contempla uma seleção dos debates da jornada, que não pretende de forma alguma esgotar a pletora de leituras que a Primeira Guerra Mundial oferece, mas sim oferecer pontos de apoio para a continuidade desses estudos por todos os interessados em compreender as guerras modernas através das narrativas que delas emergem.

O dossiê apresenta algumas leituras novas de autores canônicos do início do século XX. É o caso, por exemplo, de "Representações da alteridade na guerra: apontamentos críticos à Primeira Guerra Mundial em Virginia Woolf e Thomas Mann”, trabalho de Luiz Henrique Coelho que busca aproximar a modernista inglesa do autor alemão em suas posturas críticas ao conflito evidenciadas em textos como A Montanha Mágica, Doutor Fausto e Mrs. Dalloway. 
Larissa Guevara e Volker Jaeckel também buscam oferecer nova luz a um romance canônico em seu artigo "Nada de Novo no Front: Reflexões sobre a Grande Guerra", onde o clássico romance de Erich Maria Remarque, escrito após sua experiência de guerra, é lido à luz do livro documental Vozes Esquecidas da Primeira Guerra Mundial, de Max Arthur, de forma a explorar os pontos de contato entre a história de Paul Bäumer e os relatos reais de veteranos da guerra.

Ainda oferecendo novos olhares sobre o cânone da Primeira Guerra, Marina Naves e Valéria Pereira apresentam, em "On being asked for a war poem: W. B. Yeats and the role of the poet during World War I", como a "crise de representação" da guerra causou oscilações na postura do poeta irlandês em relação ao conflito em diferentes momentos de sua vida e obra - particularmente na compreensão de Yeats sobre o "papel do poeta" em um momento de guerra.

Outros trabalhos do dossiê se ocupam de investigar narrativas do período da guerra que não foram alçadas ao cânone da literatura do conflito. O artigo de Denise Borille, "Rebecca West e a escrita feminina da Primeira Guerra em The Return of the Soldier" é um exemplo; no trabalho, Borille investiga uma narrativa que configura um exemplo de literatura de guerra cujo escopo foge ao cânone: a escrita feminina. Ao longo de seu artigo, a pesquisadora explora como o trauma da Primeira Guerra afeta igualmente homens e mulheres no romance de Rebecca West.

O trabalho do dramaturgo austríaco Hugo von Hofmannsthal é certamente canônico - contudo, a leitura que Helmut Galle faz de sua última peça, $A$ Torre, em seu artigo "Do Sonho à Torre: O último drama de Hofmannsthal como reação à Primeira Guerra", oferece uma nova perspectiva sobre a obra do autor. Ao buscar entender à luz de Benjamin, Weber e Schmitt a derradeira peça de Hofmannsthal, publicada em 1928, como uma alegoria sobre o impacto da guerra na sociedade austríaca, Galle oferece um olhar novo sobre o texto, além de desenvolver uma importante reflexão sobre o contexto de surgimento do fascismo na Europa no entreguerras.

Thomas Burns, em seu artigo "The Great War and Anglo-American Literature: Before and After" estabelece uma ponte entre os demais trabalhos do dossiê. Em seu texto, Burns apresenta um panorama da literatura inglesa e estadunidense da Primeira Guerra - partindo de um de seus nomes mais canônicos, Ernest Hemingway, até chegar a narrativas muito menos consagradas, como The Middle Parts of Fortune, de Frederick Manning. Após discutir as obras de veteranos e contemporâneos à guerra, Burns se dedica a mapear outras narrativas anglófonas sobre o conflito escritas na segunda metade do século XX, especialmente entre as décadas de 1970 e 1990. Esse esforço de mapear as narrativas posteriores à guerra também é empreendido nos dois artigos restantes do dossiê - embora focados agora não na literatura, mas no cinema.

Ana Carolina Fernandes discute o longa-metragem A Grande Guerra, de 1959, em seu artigo "Glória Feita de Sátira: A Grande Guerra de Mario Monicelli", e explora como a Primeira Guerra Mundial se torna um palco ideal para Monicelli redefinir os paradigmas de representação cinematográfica italianos, consolidados pelo fascismo. Ao analisar o uso das estratégias narrativas da commedia all'italiana para desenvolver uma narrativa de guerra cínica e tragicômica no longa-metragem, Fernandes explora os pontos de contato e ruptura entre o filme de Monicelli e o cinema de propaganda fascista. 
Por fim, o trabalho assinado por mim, José Otaviano da Mata Machado, debruça-se sobre um longa-metragem lançado um século após o conflito. Em "Mulher Maravilha: Um filme de Segunda Guerra Mundial ambientado na Primeira Guerra Mundial”, busca-se investigar as estratégias narrativas que são operadas na memória contemporânea da Primeira Guerra Mundial no filme de 2017. Ao confrontar a adaptação da clássica personagem de quadrinhos para o cinema com os modos de representação hegemônicos da Primeira e da Segunda Guerra Mundial, pretende-se evidenciar como há um anacronismo estético no filme que implica em contradições de natureza política e ética no longa-metragem.

As narrativas exploradas nesse dossiê percorrem todo o século XX, partindo de obras escritas ainda sob o calor da guerra, chegando a outras produzidas cem anos após seu término. As vozes que narram essas estórias de guerra também são múltiplas: homens e mulheres, alemães, ingleses, austríacos, italianos, irlandeses e estadunidenses. Os gêneros e mídias percorridos são também diversos, passando pelo romance, pela poesia lírica, pela dramaturgia e pelo cinema. Ao percorrer esse amplo percurso analítico, esse dossiê pretende oferecer um panorama para entusiastas e estudiosos das narrativas da Primeira Guerra Mundial.

100 anos depois dos eventos que abalaram a Europa e o mundo entre 1914 e 1918, muitos dos fantasmas do século XX parecem rondar a aurora do século XXI. Com o ressurgimento dos diversos nacionalismos, o recrudescimento de políticas de estado autoritárias e o crescente descaso para com grupos minoritários historicamente excluídos, comparações com o período das guerras mundiais se tornam cada vez mais comuns. Voltar o olhar para os discursos produzidos pela Primeira Guerra Mundial se torna, nesse momento, mais que um interesse acadêmico, uma missão humanitária. Os membros do Núcleo de Estudos de Guerra e Literatura têm a esperança de que, a partir desse dossiê, um pequeno - mas importante - passo possa ser dado nesse sentido.

\section{REFERÊNCIAS BIBLIOGRÁFICAS}

FUSSEL, Paul. The Great War and Modern Memory. Nova Iorque: Oxford UP, 2000.

HOBSBAWM, Eric. A Era dos Extremos: O breve século XX 1914 - 1991. Trad. Marcos Santarrita. São Paulo: Companhia das Letras, 1995.

A Era dos Impérios 1875 - 1914. Trad. Sieni Maria Campos e Yolanda Steidel de Toledo. Rio de Janeiro: Paz e Terra, 2018.

NORRIS, Margot. Writing War in the Twentieth Century. Charlottesville: University Press of Virginia, 2000.

PROST, Antoine. War Losses. In: International Encyclopedia of the First World War. Berlim: Freie Universität, 2014. Digital. Disponível em: $<$ https://encyclopedia.1914-1918-online.net/article/war_losses $>$ 